\title{
Economic analysis of an integrated anthropogenic carbon dioxide network for capture and enhanced oil recovery along the Texas Gulf Coast
}

GCCC Digital Publication Series \#09-18

\author{
Carey W. King \\ Gürcan Gülen \\ Joseph Essandoh-Yeddu \\ Susan Hovorka
}

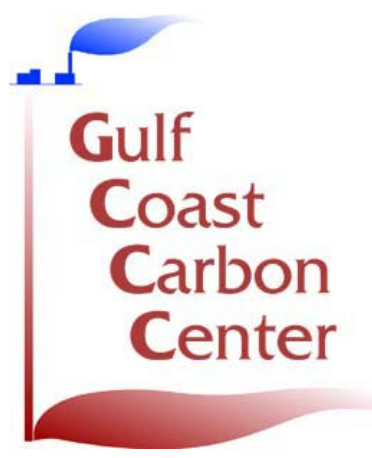

Keywords:

CO2-EOR economics, Whole system economics, Regional study-Gulf Coast

Cited as:

King, C., Gülen, G., Essandoh-Yeddu, J. and Hovorka, S., Economic analysis of an integrated anthropogenic carbon dioxide network for capture and enhanced oil recovery along the Texas Gulf Coast," Paper ES2009-90415, Proceedings of the

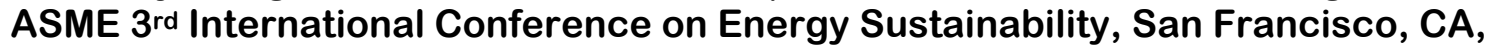
July 19-23, 2009. GCCC Digital Publication Series \#09-18. 
Proceedings of ES2009

Energy Sustainability 2009

July 19-23, 2009, San Francisco, California, USA

ASME ES2009-90415

\section{ECONOMIC ANALYSIS OF AN INTEGRATED ANTHROPOGENIC CARBON DIOXIDE NETWORK FOR CAPTURE AND ENHANCED OIL RECOVERY ALONG THE TEXAS GULF COAST}

\author{
Carey W. King \\ Research Associate, \\ Center for International Energy and \\ Environmental Policy \\ University of Texas, \\ Austin, TX 78713, USA \\ careyking@mail.utexas.edu
}

\author{
Gürcan Gülen \\ Senior Energy Economist, \\ Center for Energy Economics \\ Bureau of Economic Geology \\ University of Texas, \\ Houston, TX 77019, USA \\ gurcan.gulen@beg.utexas.edu \\ Susan Hovorka \\ Senior Research Scientist, \\ Bureau of Economic Geology \\ University of Texas, \\ Austin, TX 78713, USA \\ susan.hovorka@beg.utexas.edu
}

\author{
Joseph Essandoh-Yeddu \\ University of Cape Coast, Ghana \\ (Visiting Fellow) \\ Bureau of Economic Geology \\ University of Texas, \\ Austin, TX 78713, USA \\ jeyeddu@hotmail.com
}

\begin{abstract}
This paper explains the system economics of an example integrated network that uses anthropogenic $\mathrm{CO}_{2}$ from Texas Gulf Coast fossil power plants for enhanced oil recovery (EOR). These $\mathrm{CO}_{2}$ sources and sinks are connected via a pipeline network. A discounted cash flow model indicates that for all candidate oil fields that require less than an estimated \$10/BBL in EOR capital expenditure, all three entities $\left(\mathrm{CO}_{2}\right.$ capture, pipelines, and EOR operators) can have $20 \%$ internal rate of return at $\$ 55$ per tonne of $\mathrm{CO}_{2}$ and $\$ 56$ per barrel of oil. These results include no existing or future tax incentives, and there are some costs not yet included. However, a Monte Carlo analysis shows insight by indicating that the total system rate of return is most sensitive to oil production parameters. Oil price and estimated amount of recoverable oil are the most positively influential factors while the EOR capital cost is the most negatively sensitive factor. The capital costs of capture and $\mathrm{CO}_{2}$ price are less sensitive, both negatively affecting rate of return.
\end{abstract}

Keywords: carbon dioxide, capture, sequestration, enhanced oil recovery, economics

\section{INTRODUCTION}

Texas has played a pivotal role in the history of the energy industry and will continue to play a major role into the future. This future will likely include a price on emissions of greenhouse gases of which carbon dioxide $\left(\mathrm{CO}_{2}\right)$ is a major component. By planning ahead for this future "carbon constrained world", Texas can not only mitigate the negative economic impact to Texas industries, but may actually profit relative to other states and countries. The reason for this is that Texas can use $\mathrm{CO}_{2}$ in enhanced oil recovery (EOR) operations. The revenue from the resulting oil sales can help pay for infrastructure utilized to capture and sequester $\mathrm{CO}_{2}$ after the recoverable oil has been removed. The use of anthropogenic $\mathrm{CO}_{2}$ for Texas EOR can act as a springboard for Texas companies and workers to gain further expertise in EOR and geologic sequestration techniques such that Texas can export this knowledge to the rest of the world. This paper explains an example scenario network that can use anthropogenic $\mathrm{CO}_{2}$ for EOR using a subset of the Texas Gulf Coast resources.

In 2008 Texas was the number one producer of both oil and natural gas in the United States. Part of this success is due to the capability of the oil and gas industry to use newer exploration and production techniques to obtain resources from previously unobtainable locations such as shale. In particular, what is now common in Texas is the use of carbon dioxide $\left(\mathrm{CO}_{2}\right)$ in enhanced oil recovery (EOR) tertiary recovery operations in the Permian Basin. The overwhelming 
majority of $\mathrm{CO}_{2}$ used for this EOR production obtained from natural sources in New Mexico and Colorado.

There are many additional oil reservoirs in the state that could economically produce oil using EOR techniques, but the $\mathrm{CO}_{2}$ is generally unavailable. The Texas Legislature has previously recognized this potential by passing tax incentives in HB 3732 (2007) for the use of anthropogenic $\mathrm{CO}_{2}$ in EOR and subsequent sequestration. Additionally, the Energy Independence and Security Act of 2007 created monetary incentives for using anthropogenic $\mathrm{CO}_{2}$ for EOR. No entity is currently taking advantage of these incentives as there is no readily available source of anthropogenic $\mathrm{CO}_{2}$ in Texas. Some companies now have plans to use anthropogenic $\mathrm{CO}_{2}$ for EOR in Texas.

Along the Texas Gulf Coast region there are many point sources of $\mathrm{CO}_{2}$ as well as oil reservoirs in decline that could benefit from available $\mathrm{CO}_{2}$. This report discusses a scenario that matches some of these $\mathrm{CO}_{2}$ sources and oil reservoirs. By facilitating such a scenario, the state of Texas can play a technical and environmental leadership role for both energy and environment concerns while at the same time create economic and employment benefits for the state that help Texas transition to a new energy future.

This paper first explains the scale of $\mathrm{CO}_{2}$ emissions in Texas, the U.S. and the world. Then, in describing the Gulf Coast region of Texas, seven existing candidate anthropogenic $\mathrm{CO}_{2}$ sources are matched with twenty-two major oil fields. The multiple input sources and multiple consumers are connected via an integrated pipeline network that provides operational flexibility at both ends of the pipe. The conceptual project scenario presented in this report is only a very high level view of the basic constituents and costs. There are many other important ideas and details that will have to be determined before an integrated $\mathrm{CO}_{2}$ system can become a reality.

\section{ANALYSIS BACKGROUND AND ASSUMPTIONS}

In 2005, Texas emitted 625 million metric tons of $\mathrm{CO}_{2}-$ over $2 \%$ of the world's $\mathrm{CO}_{2}$ and $10.4 \%$ of the U.S. total [1, 2]. Texas emits more $\mathrm{CO}_{2}$ than any state in the country. This emission rate is not without justification as Texas refines much of the nation's oil and produces a disproportionate share of chemicals and other industrial goods. Thus, Texas does much of the nation's 'dirty work', and as consumers continue to purchase goods from Texas industries, Texas economy as a whole need not disproportionately suffer under greenhouse gas regulation and policy.

In fact, Texas can benefit from matching producers of $\mathrm{CO}_{2}$ to consumers of $\mathrm{CO}_{2}$. Primarily, these producers can be large electricity generation plants ranging in installed capacity from a few hundred MW to over 2,000 MW. The consumers are reservoir owners that control mineral rights to the oil in place. Over the past 35 years, a long distance $\mathrm{CO}_{2}$ pipeline network has been constructed and used for EOR in West
Texas. This $\mathrm{CO}_{2}$ is obtained from natural $\mathrm{CO}_{2}$ reservoirs. Not until climate concerns have become paramount had there been much reason to connect anthropogenic sources of $\mathrm{CO}_{2}$ to geologic sinks for either pure permanent sequestration or EOR purposes.

A large share of Texas' $\mathrm{CO}_{2}$ emissions exists along the Gulf Coast and southern central and east Texas. Within 100 miles of the Texas coast, there is over 8,000 MW of installed coal power plant capacity. There is also over 4,600 MW of natural gas generation capacity with generation units above 400 MW. Additionally, many oil reservoirs in decline exist along the Texas coast from Brownsville to Beaumont. No pipeline currently exists to connect fossil power plants as $\mathrm{CO}_{2}$ generators (sources) to EOR reservoirs as consumers (sinks).

This section describes an example scenario for combing specific power plants to specific EOR candidate oil reservoirs via an integrated multi-input multi-output (MIMO) pipeline network. The advantage of this MIMO approach is that there is flexibility for any given power plant to temporarily halt power generation and $\mathrm{CO}_{2}$ supply due to unforeseen or planned maintenance without unduly affecting EOR operations at a particular field. On the other side of the pipeline, any given oil field is able to halt intake of $\mathrm{CO}_{2}$ for any operational reasons without unduly affecting operations at any one given power plant. This advantage of the MIMO approach mimics that of the electricity transmission system where there are multiple generators (power plants), multiple consumers (homes, businesses, and industry), and an openaccess transmission network (power lines) connecting generators to consumers.

\subsection{Candidate EOR Fields}

Previous work performed at the Gulf Coast Carbon Center (GCCC) of the Bureau of Economic Geology (BEG) categorized and identified oil reservoirs that would be candidates for $\mathrm{CO}_{2}$-based EOR [3]. Throughout Texas over 1,700 oil reservoirs were identified that can be flooded with $\mathrm{CO}_{2}$ to produce extra oil through EOR [3]. The estimated total EOR production from each reservoir varies from tens of thousands to hundreds of millions of barrels (BBL).

Instead of considering all oil fields in Texas, the GCCC created selection criteria to find a subset of oil fields in the Gulf Coast region where EOR is a possibility. Reservoirs that are candidates for $\mathrm{CO}_{2}$ EOR are those that are at an advanced stage of waterflooding or aquifer encroachment [3]. One of these criteria was a future EOR minimum lifetime field production of 13 million BBL when assuming a 15\% recovery of original oil in place via EOR. Additional feasibility criteria considered the geology of the reservoirs to only include those reservoirs that can use the miscible $\mathrm{CO}_{2}$ EOR method [3]. No reservoirs were included as candidates for $\mathrm{CO}_{2}$ EOR unless the reservoir minimum miscibility pressure (MMP) was less than the initial reservoir pressure. This excludes reservoirs for which miscible $\mathrm{CO}_{2}$-based EOR is not effective. 
Table 1. Upper and lower bounds are given for the important operational parameters that govern the candidate oil fields analyzed in this

\begin{tabular}{|c|c|c|c|}
\hline EOR Operational Parameters & units & Lower Bound & Upper Bound \\
\hline \multicolumn{4}{|l|}{$\mathrm{CO}_{2}$ requirements } \\
\hline Gross $\mathrm{CO}_{2}$ injected during EOR ${ }^{\#}$ & Mscf/BBL* & 5 & 15 \\
\hline Gross $\mathrm{CO}_{2}$ injected during EOR & tonne/BBL & 0.26 & 0.79 \\
\hline Recycled $\mathrm{CO}_{2}$ injected during EOR ${ }^{\#}$ & Mscf/BBL* & 2 & 9 \\
\hline Recycled $\mathrm{CO}_{2}$ injected during EOR & tonne/BBL & 0.11 & 0.47 \\
\hline Net $\mathrm{CO}_{2}$ sequestered during $\mathrm{EOR}^{\#}$ & Mscf/BBL* & 3 & 6 \\
\hline Net $\mathrm{CO}_{2}$ sequestered during $\mathrm{EOR}$ & tonne/BBL & 0.16 & 0.32 \\
\hline \multicolumn{4}{|l|}{ Oil Production } \\
\hline $\begin{array}{c}\text { Cumulative production of all candidate } \\
\text { reservoirs }{ }^{\wedge}\end{array}$ & BBL & 5,500 million & 5,500 million \\
\hline $\begin{array}{c}\text { Original Oil in Place (OOIP) in candidate } \\
\text { reservoirs^ }\end{array}$ & BBL & $\begin{array}{l}\text { Twice cumulative } \\
\text { production }\end{array}$ & $\begin{array}{l}\text { Twice cumulative } \\
\text { production }\end{array}$ \\
\hline $\begin{array}{l}\text { Production of OOIP achievable by } \\
\qquad \mathrm{CO}_{2}-\mathrm{EOR}^{\#}\end{array}$ & $\%$ & 7 & 20 \\
\hline
\end{tabular}

\# [4]; ^ [3]; * Mscf/BBL is 1,000 standard cubic feet of $\mathrm{CO}_{2}$ per barrel of oil from EOR. $19 \mathrm{Mscf}^{\mathrm{CO}_{2}} \sim 1$ metric tonne $\mathrm{CO}_{2}$.

Out of the complete list of Texas EOR-candidate oil fields there were 26 major fields, composed of 115 reservoirs.

There are known and unknown parameters that make the predetermination of the ultimate quantity of oil produced via EOR an inherently uncertain quantity. However, a few major oil field parameters are needed to determine the size and scope of the integrated $\mathrm{CO}_{2}$ network that is required to deliver the needed $\mathrm{CO}_{2}$ for EOR. Table 1 displays the major EOR and reservoir operational parameter ranges that were used to predict the quantity of oil that is recoverable from the candidate reservoirs. These parameters ultimately project the number of power plants required to supply the $\mathrm{CO}_{2}$ to the oil fields.

The recoverable oil via $\mathrm{CO}_{2}$-based EOR can range from $7 \%-20 \%$ of the estimated original oil in place (OOIP) [4]. By using the upper and lower bounds of $\mathrm{CO}_{2}$ required per BBL of oil from $\mathrm{CO}_{2}$-flooding, the amount of $\mathrm{CO}_{2}$ required is estimated. The amount of $\mathrm{CO}_{2}$ injected (i.e. gross $\mathrm{CO}_{2}$ injected) in traditional $\mathrm{CO}_{2}$-flooding is greater than the actual amount of $\mathrm{CO}_{2}$ stored (i.e. net $\mathrm{CO}_{2}$ purchased and injected) because $\mathrm{CO}_{2}$ produced with oil is recycled and re-injected [4].

The estimated recoverable oil from the 26 candidate major oil fields is $780-2,240$ million BBL. In order to extract this oil using existing practices, a net of $120-710$ million metric tonnes of $\mathrm{CO}_{2}\left(\mathrm{MtCO}_{2}\right)$, will be required.

Figure 1 shows the general profile of the expected oil production from the candidate oil reservoirs. This production profile is chosen to fit within a 20-year schedule and represents an abstraction of typical profiles from EOR production that reach peak production in 4-5 years followed by a steady decline until no oil is produced.

The required net $\mathrm{CO}_{2}$ injected is assumed to follow a similar profile as the oil production except peaking 1-2 years earlier (Figure 1). An annual average over 20 years of 6 - 35
$\mathrm{MtCO}_{2} / \mathrm{yr}$ would be required to be delivered to the EOR field, for $120-710 \mathrm{MtCO}_{2}$ total, respectively. This annual $\mathrm{CO}_{2}$ rate represents a situation where $\mathrm{CO}_{2}$ is captured and injected at a constant rate over the 20-yr time span assumed for the EOR fields. Additionally, there can be $\mathrm{CO}_{2}$ captured at the power plants that cannot be used for EOR, but can be injected into the depleted reservoirs that are no longer producing oil. This $\mathrm{CO}_{2}$ is represented by the green region of Figure 1.

\subsection{Candidate Power Plants}

The assumption of this report is that there are available point sources of $\mathrm{CO}_{2}$ emissions in the Gulf Coast region that can supply the required $\mathrm{CO}_{2}$ for the candidate oil fields. Thus, this report only discusses the retrofitting of existing power plants based upon pulverized coal or petroleum coke burning technology. This assumption necessarily neglects the analysis of building any new power plants specifically designed from the ground up to capture $\mathrm{CO}_{2}$. Therefore, the construction of new integrated gasification combined cycle power plants, such as the designs considered for the former Department of Energy FutureGen program, is not considered.

There are three available process technologies which can in principle be used to capture $\mathrm{CO}_{2}$ from flue gases of power plants, (many more in various levels of research and development) namely [5]:

- Absorption processes where the $\mathrm{CO}_{2}$ capture is accomplished through separation with sorbents/solvents.

- Membrane processes where $\mathrm{CO}_{2}$ is selectively removed from a gaseous stream using membranes made up of polymeric and metallic ceramics.

- Liquefaction and distillation processes where $\mathrm{CO}_{2}$ is removed through a cycle of compression and distillation. 


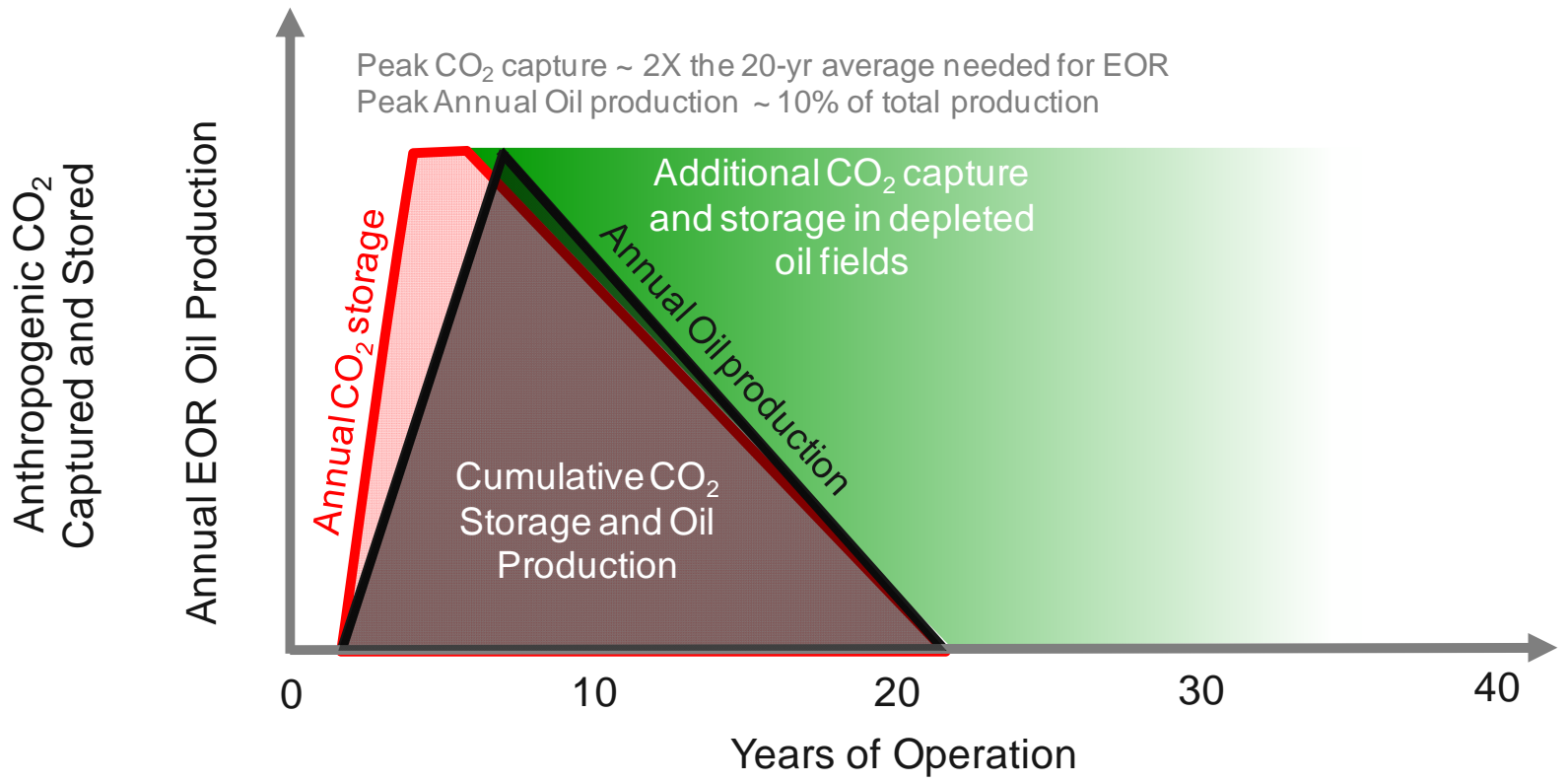

Figure 1. The analyzed scenario assumes that a maximum rate of approximately 2 times the average amount needed $\left(6-35 \mathrm{MtCO}_{2}\right)$ for the assumed 20-yr EOR project lifetime. After the locations in the EOR fields no longer viably produce oil, those same fields can potentially be used as $\mathrm{CO}_{2}$ sequestration locations for another 10-30 years after EOR production ceases.

Of the three, absorption processes based on amines are said to currently offer high capture selectivity and have relatively well-known energy use and costs. The absorption processes is the most advanced commercial process that is currently being used worldwide. Thus, we assume an amine $\mathrm{CO}_{2}$ absorption process will be retrofitted onto the existing power plants in Table 2.

The amine capture chemical process requires heat in the form of steam to release the captured $\mathrm{CO}_{2}$ from the absorbing amine such that the amine is 'regenerated' and ready to capture more $\mathrm{CO}_{2}$. This steam used the capture plant would otherwise be used to run through the plant turbines for generating electricity. For new coal plants with the same net power generation, approximately $43-48 \%$ more coal is required to generate more heat (steam) and electricity to run the amine capture process and compress the $\mathrm{CO}_{2}$ for pipeline transmission [6]. Approximately $14 \%-20 \%$ of the extra needed energy goes into gross electric power generation for pumping and $\mathrm{CO}_{2}$ compression. In retrofitting an existing power plant with a $\mathrm{CO}_{2}$ capture plant, the plant operator has the option of constructing an additional boiler, turbine, and generator to create the additional heat, steam, and power required by the $\mathrm{CO}_{2}$ capture process. For a retrofitted subcritical pulverized coal plant a similar estimate of $33 \%-42 \%$ of the gross energy of the power plant (coal input) is assumed allocated to capture process [5 - Table 3.8].

Because the amine post-combustion capture process has been practiced in industry, albeit at a smaller scale, it sets a target for newer technologies to beat. Because the auxiliary energy requirements are high and the associated added infrastructure will be on the scale of an existing coal plant, there exist ample incentives to find new $\mathrm{CO}_{2}$ capture technology. Thus, by assuming amine post-combustion capture, we believe we are estimating near an upper cost bound.

For the calculations of this report, a value of $42 \%$ is assumed as the percentage of net equivalent power (electricity) of the power plant must be diverted as heat and auxiliary power used for $\mathrm{CO}_{2}$ capture. For example, if a power plant before retrofit for $\mathrm{CO}_{2}$ capture has a $500 \mathrm{MW}$ net power capacity, after retrofit its net power capacity is assumed as 290 MW when using existing infrastructure to power the $\mathrm{CO}_{2}$ capture process.

The cost range used in this report for $\mathrm{CO}_{2}$ capture infrastructure originates from the special report by the Intergovernmental Panel on Climate Change: Carbon Dioxide Capture and Storage [5]. This report summarizes cost estimates from peer-reviewed literature discussing economics of $\mathrm{CO}_{2}$ capture. The assumed cost of the capture plant is $\$ 600$ - \$1,600 per $\mathrm{kW}$ of the subtracted power generation and heat capacity [5]. The cost range is very large and results from the fact that all costs are estimates based upon modeling because no systems at the scale of a power plant have been constructed. The reference case economic scenario described later uses the middle value of $\$ 1,100 / \mathrm{kW}$.

The capital investment for retrofitting power plants assumes (1) a chemical amine plant that absorbs $\mathrm{CO}_{2}$ from the plant flue gas, (2) dehydration and compression equipment that increases the pressure of $\mathrm{CO}_{2}$ to levels required for pipeline transmission, and (3) the capital plant design where 
existing steam and plant power generation is used to operate the $\mathrm{CO}_{2}$ capture processes, thus reducing the net power capacity of the plant during $\mathrm{CO}_{2}$ capture (Table 2).

Table 2. Candidate power plants and their parameters for retrofitting with post-combustion $\mathrm{CO}_{2}$ capture and compression infrastructure for capturing $\mathbf{9 0 \%}$ of $\mathrm{CO}_{2}$ emissions. Capturing $\mathrm{CO}_{2}$ from only a subset of the listed plants and boiler units is sufficient to supply the candidate EOR fields. SUB = subbituminous coal, LIG = lignite, $P C=$ petroleum coke.

\begin{tabular}{|c|c|c|c|}
\hline $\begin{array}{c}\text { Candidate } \\
\text { Plant } \\
\text { Names }\end{array}$ & $\begin{array}{c}\text { Installed } \\
\text { Capacity } \\
\text { (MW) }\end{array}$ & $\begin{array}{c}\text { Potential } \\
\mathrm{CO}_{2} \\
\text { capture } \\
\left.\text { (MtCO }_{2} / \mathrm{yr}\right)^{\circ}\end{array}$ & $\begin{array}{l}\text { Subtracted } \\
\text { Plant } \\
\text { Capacity } \\
\text { (MW) }\end{array}$ \\
\hline $\begin{array}{l}\text { Coleto Creek } \\
\text { (SUB) }\end{array}$ & 570 & 3.9 & 239 \\
\hline $\begin{array}{c}\text { San Miguel } \\
\text { (LIG) }\end{array}$ & 410 & 2.8 & 172 \\
\hline $\begin{array}{c}\text { J.K. Spruce } \\
\text { (SUB) }\end{array}$ & 546 & 3.8 & 229 \\
\hline $\begin{array}{l}\text { J.T. Deely } \\
\text { (SUB) }\end{array}$ & 892 & 6.2 & 375 \\
\hline $\begin{array}{c}\text { AES } \\
\text { Deepwater } \\
(\mathrm{PC})\end{array}$ & 184 & 1.3 & 77 \\
\hline $\begin{array}{l}\text { W.A. Parish } \\
\text { (SUB) }\end{array}$ & 2,700 & 20.0 & 1,135 \\
\hline $\begin{array}{c}\text { Fayette } \\
\text { Project (SUB) }\end{array}$ & 1,690 & 11.7 & 710 \\
\hline TOTAL & 8,260 & 50 & 2,937 \\
\hline
\end{tabular}

${ }^{\circ}$ Power plants are assumed to operate at $85 \%$ capacity factor, $90 \%$ of $\mathrm{CO}_{2}$ emissions captured. The $\mathrm{CO}_{2}$ emissions are approximately $0.15 \mathrm{tCO}_{2} / \mathrm{MWh}$ of net generation during $90 \%$ capture.

* The Subtracted Plant Capacity is the existing plant power and heat that is assumed used to operate the $\mathrm{CO}_{2}$ capture processes.

It is important to note that the summer peak power capacity of the power plants with $\mathrm{CO}_{2}$ capture can be the same as without $\mathrm{CO}_{2}$ capture by turning off the $\mathrm{CO}_{2}$ capture process during the peak demand times [7-9]. Turning the $\mathrm{CO}_{2}$ capture off during summer peak demand (hours, days, or months) is an option that is likely feasible for avoiding the higher capital investment costs associated with constructing more power plant capacity. Each power plant is assumed to operate at $85 \%$ capacity factor over the course of each year while capturing $90 \%$ of total $\mathrm{CO}_{2}$ emissions. The average $\mathrm{CO}_{2}$ emissions rate of the existing Texas coal power plant fleet is approximately 1.03 metric tonnes ${ }^{1}\left(\mathrm{tCO}_{2}\right)$ per net megawatthour (MWh) exported to the electric grid [10]. After capturing $90 \%$ of emissions from a coal plant, the emissions rate of net generation is estimated at $0.15 \mathrm{tCO}_{2} / \mathrm{MWh}$.

From looking at the candidate power plant list in Table 2, not all of the power plants will require $\mathrm{CO}_{2}$ capture systems to

\footnotetext{
11 metric tonne $=1.102$ short tons
}

supply the $\mathrm{CO}_{2}$ for the EOR fields. For the 20-year EOR field lifetime assumed in this report, an average of $6-35 \mathrm{MtCO}_{2} / \mathrm{yr}$ is required. Thus, for the low end of the range of $\mathrm{CO}_{2}$ requirements, only 2-3 power plants (1,000 MW of existing net power capacity) would be required for retrofit. However, for the upper end of the $\mathrm{CO}_{2}$ requirements, 4-6 of the power plants (up to 5,250 MW of net capacity) would require $\mathrm{CO}_{2}$ capture installation on some or all of their generation units.

\subsection{Pipeline Network}

Capturing and compressing $\mathrm{CO}_{2}$ for transport via pipelines is not a new engineering feat, but filling a pipeline with anthropogenic carbon dioxide from multiple sources to multiple locations will be new. However, some private industry companies operating in Texas are currently planning on being part of the value chain from capturing $\mathrm{CO}_{2}$ from fossil power plants to injecting it into the ground for EOR and sequestration [11]. A few other initial plans exist for supplying anthropogenic $\mathrm{CO}_{2}$ to both the Permian Basin and specific East Texas oil fields.

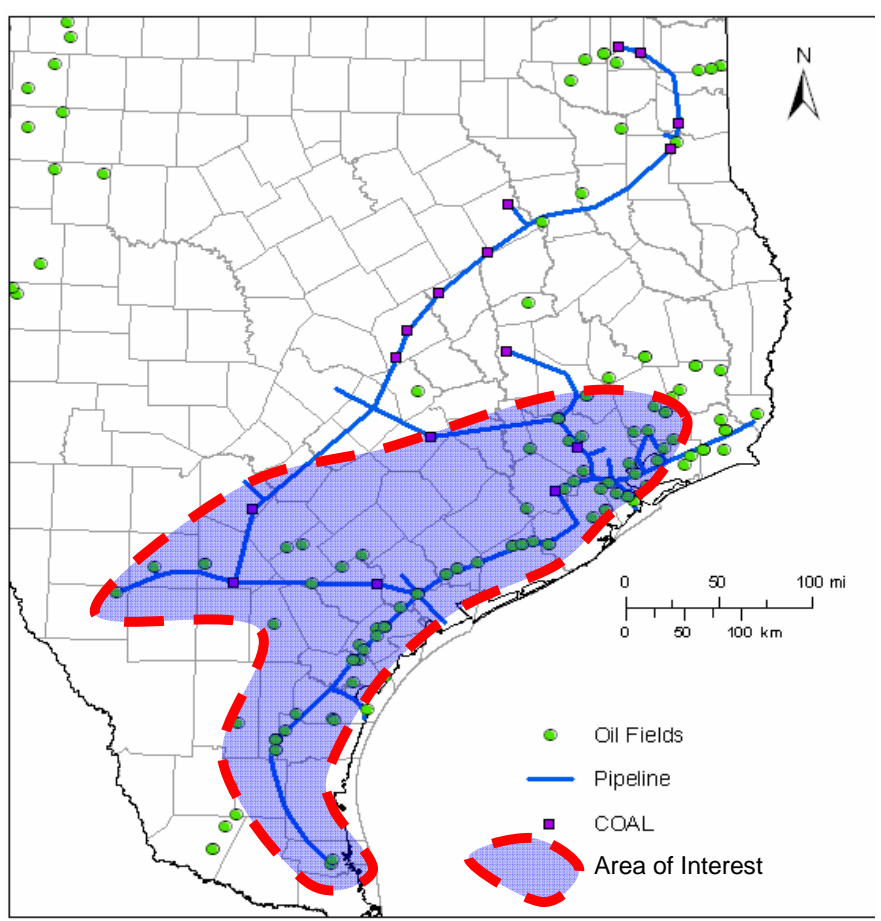

Figure 2. The area of interest analyzed in this report is mostly the area within $\mathbf{1 0 0}$ miles of the Gulf Coast from Houston almost to Harlingen and could include coal power plants as inland as Bexar and Fayette Counties.

An integrated pipeline network was designed to connect the candidate EOR reservoirs with all seven of the selected power plants ${ }^{2}$. Figure 2 indicates the area of interest in the

${ }^{2}$ All seven power plants were selected as to estimate a reference pipeline path to serve EOR fields in the upper range total pipeline length needed for oil production and $\mathrm{CO}_{2}$ requirements. 
shaded region and shows the relative position of the major pipeline sections. Note that there are many other viable pipeline paths that can connect the selected power plants to candidate oil reservoirs. The total pipeline path is approximately 1,000 miles long composed of pipes varying in diameter from several inches to a few feet. The preliminary pipeline paths were chosen to avoid sensitive environmental areas, state and national parks, and other restricted lands. Figure 2 shows other future pipelines that can be built to connect existing coal plants to create an even more robust integrated $\mathrm{CO}_{2}$ network.

\subsection{Costs: EOR}

There are many assumptions often made in order to predict the economic costs for oil field capital equipment and operation and maintenance $(\mathrm{O} \& \mathrm{M})$ related to EOR. In calculating the capital and O\&M costs for EOR operations one can involve many assumptions about what and how many facilities and wells already exist at the field in addition to how many new wells are to be drilled. The major assumptions are described in this section.

For production wells, no new production wells are assumed needed to be drilled. However, significant "workover" is required on the existing production wells to prepare them for the $\mathrm{CO}_{2}$ and oil solution flowing through them. Thus, the capital investment required for the wells is less than that required for drilling a new well. For the 26 candidate fields there are an estimated required 9,600 production wells, all assumed in existence. The capital cost for preparing each existing well is assumed as the sum of $50 \%$ of the cost of production equipment for a new well and $48 \%$ of new drilling and completion costs [4]. The costs for production equipment and drilling and completion costs is taken from both McCoy (2008) and Advanced Resources International (2006) to compare slightly different sources and methodologies.

We assume one injection well is needed for each production well, for a 1:1 ratio. As a conservative economic approach that will not underestimate the costs, all 9,600 injection wells are assumed new. In reality, there may be a significant number, if not all, of the injection wells that were formerly used for water flooding injection during secondary oil recovery. These former water-flooding injection wells could only require minor modifications, such as new wellheads for $\mathrm{CO}_{2}$ injection [4]. However, past industry experience indicates that converting old water injection wells for $\mathrm{CO}_{2}$ injection usually creates too many difficulties. The EOR capital costs for injection wells include lease equipment, injection equipment, and the drilling costs for the new well.

Capital costs for $\mathrm{CO}_{2}$ processing equipment are based upon the peak quantity of $\mathrm{CO}_{2}$ that needs to be processed. That is to say, the largest flow rate of $\mathrm{CO}_{2}$ that is recycled (dehydrated and compressed) when brought up from a production well dictates the required capacity size of the processing capital equipment. For the capital cost calculation, we estimate the peak recycle flow rate as the average $\mathrm{CO}_{2}$ recycle rate over the 20-year assumed field operation. The capital cost value of 700,000 \$/avg million scf $\mathrm{CO}_{2}$ processed is used for $\mathrm{CO}_{2}$ processing equipment [12].

The EOR O\&M costs are assumed as in ARI (2006) as $0.50 \$$ /Mscf of processed (recycled) $\mathrm{CO}_{2}$ plus $0.25 \$ /$ barrel of total fluid (oil, $\mathrm{CO}_{2}$, and water) lifted from the well. The value of $0.60 \$ / \mathrm{BBL}$ of oil (assuming over the life of the well that $42 \%$ of fluid lifted is oil) is used as in McCoy (2008). These amount to a final O\&M assumed cost of $\$ 5.6 / \mathrm{BBL}$.

\subsection{EOR Field Optimization for Reference Case}

After the initial screening process for choosing oil fields for EOR, we ranked them in order of increasing capital investment cost ration of $\$ / B B L$. We also assumed a reference recovery factor of $12 \%$ of the original oil in place. This choice establishes a reference case for the cash flow analysis results of Section 3.

The squares of Figure 3 show the expected cumulative oil production from the various EOR fields after ranking them from low to high capital investment ratio. The significant feature of the plot that there is a sharp change in slope at approximately $\$ 10 / \mathrm{BBL}$ and 1.2 billion BBL cumulative oil production.

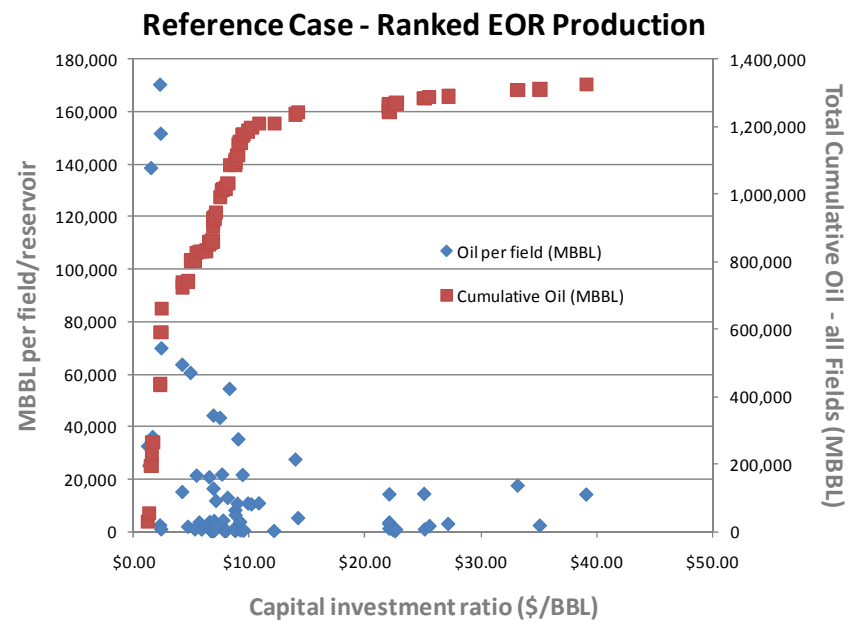

Figure 3. The difference in economic quality of the various EOR candidate fields is evident when ordering them from lowest to highest capital investment ratio (\$/BBL).

In order to see the cost implications, Figure 4 presents the same cumulative oil production alongside the cumulative capital investment. Approximately $\$ 5.6$ billion in capital investment is required for the first 1.2 billion BBL. Then another $\$ 3.3$ billion is estimated to be needed for the next 0.1 billion BBL of oil. Therefore, we choose as our reference case such that we eliminate any fields that are estimated to have a capital investment ratio of more than $\$ 10 / \mathrm{BBL}$. The reference case is $\$ 5.6$ Billion in capital investment for 1.2 billion BBL from 22 major oil fields. Figures 3 and 4 show more data than 
the 26 major candidate fields as many are composed of smaller subsidiary reservoirs that we were estimating Because we chose the fields with lowest capital investment ratio, only 6,150 production and injection wells are now estimated for the reference case.

The 22 oil fields chosen for EOR are: Big Wells (3 fields total), Borregos (10 fields total), Conroe, Fig Ridge, Giddings (2 fields total), Gillock, Goose Creek, Hastings, Hull (2 fields total), Liberty South, Orange (2 fields total), Oyster Bayou, Pearsall, Pierce Junction, Portilla, Seeligson, T-C-B, Tom O’Connor, Webster, West Ranch (8 fields total), White Point East, and Willimar.

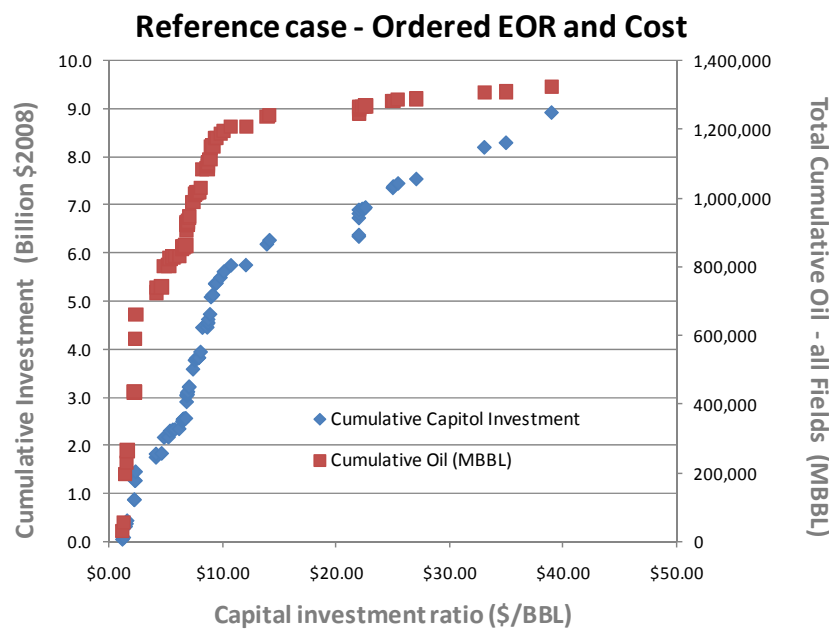

Figure 4. The trend of cumulative EOR capital cost ratio (\$/BBL) increases more slowly after $\$ 10 / \mathrm{BBL}$, but cumulative oil production also increases very slowly.

Over the life of the EOR field, we assume that the fields require a net of $0.24 \mathrm{tCO}_{2} / \mathrm{BBL}$ of oil while recycling 0.29 $\mathrm{tCO}_{2} / \mathrm{BBL}$. Thus, a total gross quantity of $636 \mathrm{MtCO}_{2}$ (at 0.53 $\mathrm{tCO}_{2}$ ) is injected into the reservoirs while $280 \mathrm{MtCO}_{2}$ remains (net) in the reservoirs. The 1.2 billion $\mathrm{BBL}$ of EOR-produced oil will emit approximately $430-500 \mathrm{MtCO}_{2}$ if all burned ${ }^{3}$, but approximately $85 \%$ of products from a BBL are eventually combusted.

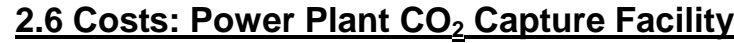

The costs for capital infrastructure and annual O\&M for operating the $\mathrm{CO}_{2}$ capture portion of the power plant varies substantially depending upon the number of power plants needed to supply $\mathrm{CO}_{2}$. A fleet of coal power plants could use one of two, or a combination, of investment and operational strategies associated with retrofitting existing power plants for post-combustion $\mathrm{CO}_{2}$ capture (see Table 3). The capital expenditure is higher when installing more gross generating capacity at a power plant in order to maintain the existing net

\footnotetext{
${ }^{3} 0.42 \mathrm{tCO}_{2} / \mathrm{BBL}$ per http://www.eia.doe.gov/oiaf/1605/coefficients.html
}

generating capacity when the capture process is running at full power. However, technology advancement could enable the shutting off of the capture process during peak demand times of the year. Determining the differences in technical and economic feasibility between each of these strategies could be a major goal of the first few full scale ( $>150 \mathrm{MW}) \mathrm{CO}_{2}$ capture plants. The annual operation and maintenance cost is the same for either strategy based upon the quantity of gross generation.

For the reference case, there is an assumed peak $\mathrm{CO}_{2}$ need of $25 \mathrm{MtCO}_{2} / \mathrm{yr}$ at a mid-range capital cost for the capture plant of $\$ 1,100 / \mathrm{kW}$ of added or subtracted plant capacity to run the capture processes. The upper and lower ranges for capital cost are $\$ 600 / \mathrm{kW}$ and $\$ 1,600 / \mathrm{kW}$ [5]. Operation and maintenance costs for running the capture plant are $19-38 \$ / \mathrm{tCO}_{2}$.

\subsection{Costs: Pipeline Network}

Connecting several power plants to a couple of dozen oil field locations will require an extensive pipeline network, but not one that is unprecedented compared to existing oil and gas pipelines in Texas. A potential pipeline path and sizing solution was designed to connect the candidate oil fields with the candidate power plants. This provides an estimate of the materials, cost, and labor associated with the integrated pipeline concept. The total pipeline length is approximately 1000 miles with diameters ranging from just a six inches (for small $\mathrm{CO}_{2}$ flow rates to small oil fields) to a 30 inches in diameter for central "backbone" portions of the pipeline that carry $\mathrm{CO}_{2}$ from multiple power plants to multiple oil fields.

Pipeline costs are spread between labor (50\%), materials (20\%), right of way (10\%), and other miscellaneous (20\%) costs [4]. Past analyses of pipeline construction cost estimates from McCoy (2008) and MIT (2003) approximately \$20,000$\$ 30,000$ per inch per $\mathrm{km}(\$ 32,000-\$ 50,000 / \mathrm{in} / \mathrm{mile})$. Thus, to estimate the cost of a pipeline segment one can multiply the diameter of the pipeline (in inches) and the length (in miles or $\mathrm{km}$ as needed). However, industry costs announcements of 2007 and 2008 indicate that pipeline costs had become significantly higher. The cost estimates of the last 2-5 years have varied over an order of magnitude, notwithstanding any possible cost reduction due to general economic downturn starting late 2008.

For the pipeline analyzed by the GCCC, the estimated installed cost for the pipeline network is $\$ 1-\$ 2$ billion. This pipeline connects all seven potential power plants of Table 2 to the candidate oil fields. The cost per unit is approximately $\$ 50,000-\$ 70,000$ per inch diameter per mile. For Annual operation and maintenance costs are estimated at approximately $2.85 \$ / \mathrm{tCO}_{2}\left(0.15 \$ / \mathrm{Mscf}\right.$ of $\left.\mathrm{CO}_{2}\right)$ transported. This is consistent with O\&M costs for natural gas pipelines and estimates from some of the proposed $\mathrm{CO}_{2}$ pipeline projects. 


\subsection{Costs: Cash Flow Input Summary}

Table 3 shows all of the final cost assumptions for estimating the cash flow for the integrated $\mathrm{CO}_{2}$ network.

Table 3. Economic Parameters used to estimate net present value of an integrated $\mathrm{CO}_{2}$ network along the Texas Gulf Coast.

\begin{tabular}{|c|c|}
\hline Economic Parameters & $\begin{array}{c}\text { Reference } \\
\text { Case }\end{array}$ \\
\hline \multicolumn{2}{|l|}{$\begin{array}{c}\text { Enhanced Oil Recovery Production } \\
\text { and Costs }\end{array}$} \\
\hline $\begin{array}{l}\text { Oil production from EOR, } 20 \text { years (million } \\
\qquad B B L \text { ) }\end{array}$ & 1,200 \\
\hline $\begin{array}{c}\text { Total EOR net } \mathrm{CO}_{2} \text { need over } 20 \text { years } \\
\left(\mathrm{MtCO}_{2}\right)\end{array}$ & 290 \\
\hline $\begin{array}{l}\text { Total EOR net } \mathrm{CO}_{2} \text { need over } 20 \text { years } \\
\text { (million } \mathrm{Mscf}^{\mathrm{CO}_{2} \text { ) }}\end{array}$ & 5,500 \\
\hline $\begin{array}{l}\text { Peak annual EOR } \mathrm{CO}_{2} \text { purchase need } \\
\left(\mathrm{MtCO}_{2}\right)\end{array}$ & 25 \\
\hline EOR capital costs (\$ million) & 5,600 \\
\hline EOR O\&M costs $(\$ / B B L)^{@}$ & 5.6 \\
\hline \multicolumn{2}{|l|}{$\mathrm{CO}_{2}$ Pipeline Costs } \\
\hline Pipeline capital cost (\$ million) & 2,000 \\
\hline $\begin{array}{c}\text { Pipeline O\&M Cost* } \\
\left(\$ / \mathrm{Mscf}^{*} \mathrm{CO}_{2}\right)\end{array}$ & 0.15 \\
\hline \multicolumn{2}{|l|}{$\mathrm{CO}_{2}$ Capture Installation and Costs } \\
\hline $\begin{array}{c}\mathrm{CO}_{2} \text { capture capital costs } \\
(\$ / \mathrm{kW} \text { for capture })^{\star \star}\end{array}$ & 1,100 \\
\hline $\begin{array}{c}\mathrm{CO}_{2} \text { capture O\&M costs } \\
\left(\$ / M s c f \mathrm{CO}_{2}\right) \\
\end{array}$ & 2.0 \\
\hline Gross equivalent power for capture (MW) & 1,500 \\
\hline $\begin{array}{l}\text { Capital Cost for } \mathrm{CO}_{2} \text { capture facilities } \\
(\$ \text { million })\end{array}$ & 1,650 \\
\hline \multicolumn{2}{|l|}{ Tax Rates and Royalties } \\
\hline State $\mathrm{Tax}$ on $\mathrm{CO}_{2}$ capture activities (\%) & 2 \\
\hline State Tax on $\mathrm{CO}_{2}$ pipeline activities (\%) & 2 \\
\hline $\begin{array}{c}\text { State Tax on EOR oil } \\
\text { (before HB } 3732 \text { incentive) }^{\#}(\%)\end{array}$ & 8.6 \\
\hline Royalty Fee for landowners (\%) & 20 \\
\hline
\end{tabular}

O\&M $=\left(1 \%\right.$ oil price per $\mathrm{BBL}$ in $\$ /$ Mscf $\mathrm{CO}_{2}$ recycled $) *(0.60 \$ / B B L$ oil). Using method from [4] Table 3.14 and [12] Appendix B plus a $10 \%$ increase to account for contingency values and inflation.

* Based on estimates by Denbury for its $\mathrm{CO}_{2}$ pipeline from Mississippi to East Texas. This is also consistent with O\&M costs for natural gas pipelines.

${ }^{* *}$ Midrange from [5].

${ }^{\#}$ HB 3732 (2007) approves an additional 50\% severance tax decrease for EOR projects that permanently sequester the Texas-originated anthropogenic $\mathrm{CO}_{2}$ after operations.

\subsection{Costs: Those not included - left for Future Work}

There are several costs for various parts of the system that were not yet included either due to lack of data, high uncertainty, or need for an augmented methodology. These costs are left for future work. Thus, the results in Section 3 are not all inclusive.

Costs not included in the analysis are:

- Measurement, monitoring, and verification costs associated with sequestration of $\mathrm{CO}_{2}$ in depleted oil fields after oil production has ceased, although pure sequestration costs are often quoted at $<\$ 10 / \mathrm{tCO}_{2}$ [5],

- Feeder $\mathrm{CO}_{2}$ pipelines in the EOR that go from the modeled pipeline dispersed throughout the field,

- The operation costs of $\mathrm{CO}_{2}$ recycling based upon the amount of $\mathrm{CO}_{2}$ recycled over time as we have yet to estimate a profile for the recycled $\mathrm{CO}_{2}$,

- The fact that there has been a historical limit on $\mathrm{CO}_{2}$ price that oil producers are willing to pay: approximately 0.30.4 for the ratio $\left(\$ / \mathrm{tCO}_{2}\right) /(\$ / \mathrm{BBL})$, and

- Existing State of Texas or federal subsidies in place to promote $\mathrm{CO}_{2}$ capture and sequestration, with or without EOR.

\section{RESULTS AND DISCUSSION}

When accounting for all of the $\mathrm{CO}_{2}$ flows of the system over the course of the 23 years of the reference integrated scenario, $280 \mathrm{MtCO}_{2}$ are stored in the depleted oil reservoirs and 430-500 $\mathrm{MtCO}_{2}$ is emitted from the recovered oil ${ }^{4}$. Thus, there is a net exchange of $270 \mathrm{MtCO}_{2}$ to the atmosphere. However, the existing reservoirs and infrastructure can be used to sequester additional $\mathrm{CO}_{2}$ after all oil has been recovered such than an estimated $560 \mathrm{MtCO}_{2}$ is eventually stored and the system over the entire life cycle is carbon neutral.

\subsection{Cash Flow assumptions}

We developed a discounted cash flow model with financing to investigate under what conditions such an integrated capture-pipeline-EOR infrastructure could be commercially viable. The EOR operator buys the $\mathrm{CO}_{2}$ from the power plants with capture it and then pays the pipeline company for transporting the $\mathrm{CO}_{2}$ to the oil field.

In addition to fundamental inputs in Table 3, the financial assumptions for the base case are: $10 \%$ discount rate; 10 year loans at a rate of $12 \%$ for $60 \%$ of capital costs ( $40 \%$ equity) $2.5 \%$ of the loan amount is paid as the up-front fee; $0.6 \%$ interest during construction. Capital investments in all infrastructure are made over 3 years (30\% first year, 50\% second year, and $20 \%$ third year).

\footnotetext{
${ }^{4}$ Oil is assumed to embody $0.42 \mathrm{tCO}_{2} / \mathrm{BBL}$ and $85-100$ percent of the full volume of the barrel is assumed burned without $\mathrm{CO}_{2}$ emissions reduction technology.
} 


\subsection{Cash Flow results}

In order for all three major parties - power plant operator, pipeline operator, and EOR field operator - to achieve $20 \%$ internal rate of return (IRR), the required long-term average prices are $\$ 55 / \mathrm{tCO}_{2}, \$ 56 / \mathrm{BBL}$ of oil, and $1.23 \$ / \mathrm{mcfCO}_{2}$ charged as a pipeline transport tariff. Although EOR operators can afford to pay $\$ 55 / \mathrm{tCO}_{2}$ as long as oil price is at least $\$ 56 / \mathrm{BBL}$, they do not have to. This price is much higher than the prices seen in European and U.S. carbon markets. In Europe after reaching a high of about $\$ 44 / \mathrm{tCO}_{2}$, the price has sunk to about $\$ 13 / \mathrm{tCO}_{2}$ in early 2009. The results imply that $\mathrm{CO}_{2}$ operations are not economically viable below \$50$\$ 60 / \mathrm{tCO}_{2}$ such that capture might have to be supported via tax credits or otherwise. Stringent climate regulation will likely increase the $\mathrm{CO}_{2}$ price but as of now there is huge uncertainty about future policies and their impacts, especially under current economic conditions.

At the same time, \$56/BBL may seem like a high price for oil in today's environment; but it appears to be a very reasonable average. The breakeven price for many marginal onshore producers is about $\$ 55-60 / \mathrm{BBL}$, especially in the U.S., and, more importantly, some analysts believe \$60/BBL is necessary for long-term sustainability of oil supplies. ${ }^{5}$ The Organization of Petroleum Exporting Countries has stated that in the future after the current economic downturn, that $\$ 70 / \mathrm{BBL}$ is a reasonable target price to induce investments [13]. Hence, it would not be prudent to assume prices higher than 60-70 \$/BBL for investment decisions.

There are many uncertainties in this system: from Table 1 , a range of 0.16 to $0.32 \mathrm{tCO}_{2} / \mathrm{BBL}$ and a range of $7 \%$ to $20 \%$ of recovery of OOIP are possible. Also, capital costs have wide ranges, especially for capture and EOR operations, and the prices of $\mathrm{CO}_{2}$ and oil are likely to be very volatile. We use Monte Carlo (MC) analysis to help frame the possible outcomes (see Table 4).

Table 4. Monte Carlo Simulation Assumptions for variable distributions.

\begin{tabular}{|c|c|c|c|}
\hline $\begin{array}{c}\text { Variable } \\
\mathrm{CO}_{2} \\
\text { purchase }\end{array}$ & Distribution & Mean & St. Dev. \\
\hline$\%$ OOIP & Log-normal & $\begin{array}{c}0.24 \\
\mathrm{tCO}\end{array} / \mathrm{BBL}$ & 0.02 \\
\hline EOR K-cost & Log-normal & $\$ 5.6$ billion & $\$ 1$ billion \\
\hline CC K-cost & Normal & $\$ 1.65$ billion & $\$ 247$ million \\
\hline Oil price & Log-normal & $\$ 56 / \mathrm{BBL}$ & $\$ 6 / \mathrm{BBL}$ \\
\hline $\mathrm{CO}_{2}$ price & Log-normal & $30 \$ / \mathrm{tCO}$ & $10 \$ / \mathrm{tCO}$ \\
\hline Pipe tariff & Normal & $\$ 1.23 / \mathrm{mcf}_{2}$ & $\$ 0.25 / \mathrm{mcf}$ \\
\hline
\end{tabular}

For EOR, we assume a log-normal distribution with $\$ 5.6$ billion as the mean because it is possible for capital costs of EOR operations to be significantly larger (as there are more uncertainties associated with EOR) but it is not likely for costs to be much lower. The oil and $\mathrm{CO}_{2}$ prices are modeled as log24, 2009. normal for similar reasons. Our reference case values are taken as the mean except for the $\mathrm{CO}_{2}$ price, which we assumed a mean of $\$ 30$ to reflect $\mathrm{CO}_{2}$ markets more realistically as discussed earlier.

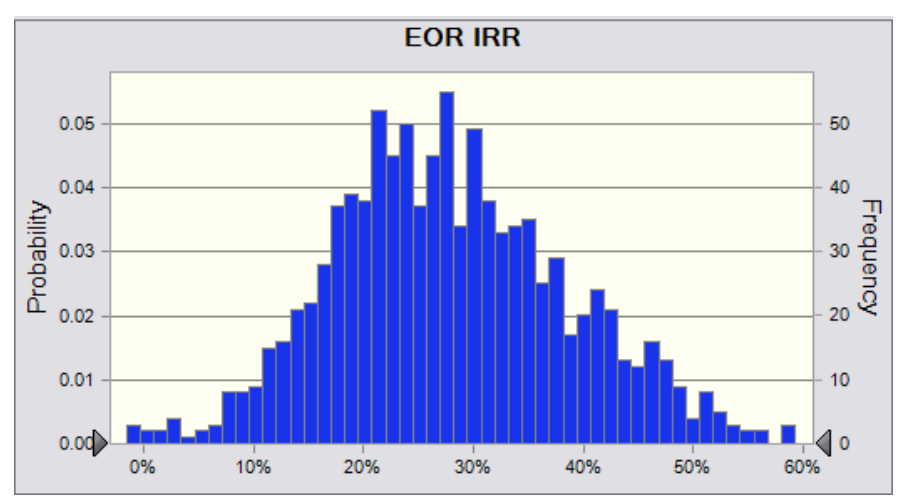

Figure 5. Monte Carlo Results: frequency distribution for EOR IRR

The cumulative impact of all these uncertainties on EOR IRR is displayed in Figure 5. There is a good chance for EOR operations to yield an IRR of $20 \%$ or greater. In Figure 6, oil price and \% of OOIP recovery are the most important variables on the positive side, explaining why the distribution for EOR IRR looks so good. The uncertainty about the capital cost is a significant risk but it is overcome by the potential higher price of oil and higher yield of the oil fields after $\mathrm{CO}_{2}$ injection. Higher $\mathrm{CO}_{2}$ prices pose a sizeable risk despite our assumption of historical $\mathrm{CO}_{2}$ price average of $\$ 30 / \mathrm{tCO}_{2}$. The need for more $\mathrm{CO}_{2}$ per barrel and higher transportation tariffs will also negatively impact EOR returns but these risks are minimal.

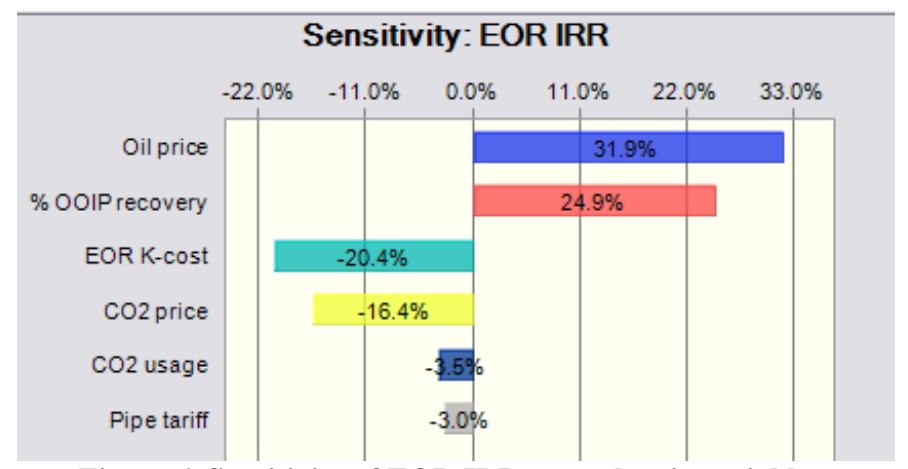

Figure 6. Sensitivity of EOR IRR to stochastic variables.

\section{CONCLUSIONS}

We developed a cash flow model for financing that integrates three segments of the $\mathrm{CO}_{2}$-EOR value chain: carbon capture at coal plants, pipeline transportation of $\mathrm{CO}_{2}$ to target oil fields and investment in EOR operations. Our reference case is for each segment to yield an IRR of $20 \%$. This raises the challenge to the EOR operators, who have to buy $\mathrm{CO}_{2}$ and pay for transportation. Nevertheless, an oil price of $\$ 56 / \mathrm{BBL}$ 
is sufficient for viability. However, $\$ 55 / \mathrm{tCO}_{2}$ that is necessary for $20 \%$ IRR in the capture segment is higher than historical prices of $\mathrm{CO}_{2}$ in cap-and-trade markets and the prices paid by existing $\mathrm{CO}_{2}$-EOR operators. There is great uncertainty about the capital cost of capture and EOR, especially given the large number of plants and fields we consider not to mention volatility of the oil price. We also considered two technical uncertainties: $\mathrm{CO}_{2}$ needed for each barrel of oil and percent of OOIP that can be recovered via EOR. Monte Carlo simulations indicate that EOR operations are more likely to yield an IRR greater than $20 \%$, mainly because we expect oil price to be higher and $\mathrm{CO}_{2}$ price to be lower than those in our reference case. However, low $\mathrm{CO}_{2}$ prices imply that capture operations will have to be supported by policy incentives. In the future, we will expand our research to look at the impact of various $\mathrm{CO}_{2}$ regulation schemes and incentives on capture, EOR, and sequestration operations.

\section{NOMENCLATURE}

BEG = Bureau of Economic Geology

$\mathrm{BBL}$ = blue barrel of oil (42 gallons)

$\mathrm{EOR}=$ enhanced oil recovery (using $\mathrm{CO}_{2}$ )

GCCC $=$ Gulf Coast Carbon Center

IRR = internal rate of return

MIMO = multi-input multi-output

$\mathrm{MtCO}_{2}=$ million metric tons of carbon dioxide

OOIP = original oil in place

$\mathrm{tCO}_{2}=$ metric ton of $\mathrm{CO}_{2}$

\section{REFERENCES}

[1] EIA. 2007. Annual Energy Outlook 2007.

[2] EIA. 2008. Environment website of EIA http://www.eia.doe.gov/environment.html.

[3] Holtz, Mark H.; Nance, Peter K.; Finley, Robert J. Reduction of Greenhouse Gas Emissions through Underground CO2 Sequestration in Texas Oil and Gas Reservoirs; EPRI, Palo Alto, CA: 1999. TR-XXXXXX, WO4603-04. Final Report. Available December 2008 at: http://www.beg.utexas.edu/environqlty/abndnhydrores/co 2text.pdf

[4] McCoy, Sean T. 2008. The Economics of CO2 Transport by Pipeline and Storage in Saline Aquifers and Oil Reservoirs. Doctoral Thesis - Carnegie Mellon University.

[5] IPCC. 2005. Carbon Dioxide Capture and Storage, Prepared by the Working Group III of the Intergovernmental Panel on Climate Change (IPCC), Cambridge University Press, 2005.

[6] DOE/NETL. 2007. U.S. Department of Energy, National Energy Technology Laboratory. Cost and Performance Comparison Baseline for Fossil Energy Power Plants. Available at: http://www.netl.doe.gov/energy-
analyses/pubs/Bituminous\%20Baseline_Final\%20Report. pdf.

[7] Lucquiaud, Mathieu; Chalmers, Hannah; Gibbins, Jon. 2008. Capture-ready Supercritical Coal-fired Power Plants and Flexible Post-combustion $\mathrm{CO}_{2}$ capture. Proceedings of the $9^{\text {th }}$ International Conference on Greenhouse Gas Technologies. November 16-20, 2008. Washington DC.

[8] Ziaii, Sepideh; Cohen, Stuart; Rochelle, Gary T.; Edgar, Thomas F.; Webber, Michael. E. 2008. Dynamic Operation of Amine Scrubbing in Response to Electricity Demand and Pricing. Proceedings of the $9^{\text {th }}$ International Conference on Greenhouse Gas Technologies. November 16-20, 2008. Washington DC.

[9] Cohen, Stuart M.; Rochelle, Gary T.; Webber, Michael E. 2008. Turning CO2 Capture On \& Off in Response to Electric Grid Demand: A Baseline Analysis of Emissions and Economics. Paper ES2008-54296, Proceedings of the ASME $2^{\text {nd }}$ International Conference on Energy Sustainability, Jacksonville, FL, August 10-14, 2008.

[10] EIA. 2006. State Electricity Profiles: Texas, 2006.

[11] Percival, Pamela. 2008. Texas may prosper by courting carbon storage. Fort Worth Basin Oil and Gas, December, 2008, pp. 22-28.

[12] ARI. 2006. Basin Oriented Strategies for CO2 Enhanced Oil Recovery: East and Central Texas. Prepared by Advanced Resources International for the U.S. Department of Energy. February, 2006.

[13] AFP. 2009. “OPEC wants oil to reach $\$ 70$ a barrel.”April 26, 2009. Available April 27, 2009 at: http://www.breitbart.com/article.php?id=CNG.b84fea41a 4937984085503f14c5e8222.b41\&show_article=1. 